\title{
Liposome bupivacaine for improvement in economic outcomes and opioid burden in GI surgery: IMPROVE Study pooled analysis
}

This article was published in the following Dove Press journal:

Journal of Pain Research

24 June 2014

Number of times this article has been viewed

\author{
Stephen M Cohen' \\ Jon D Vogel ${ }^{2}$ \\ Jorge E Marcet ${ }^{3}$ \\ Keith A Candiotti ${ }^{4}$ \\ 'Atlanta Colon and Rectal Surgery, \\ PA, Atlanta, GA, USA; ${ }^{2}$ General \\ Surgery Clinic, University of \\ Colorado, Aurora, CO, USA \\ ${ }^{3}$ Department of Surgery, Morsani \\ College of Medicine, University \\ of South Florida, Tampa, FL, USA; \\ ${ }^{4}$ Department of Anesthesiology, \\ University of Miami Leonard Miller \\ School of Medicine, Miami, FL, USA
}

Correspondence: Stephen M Cohen Atlanta Colon and Rectal Surgery, PA, 33 Upper Riverdale Road, \#127, Riverdale, GA 30274, USA

Tel +I 770997 I 975

Fax + I 7709971966

Email stephencohen615@gmail.com
Abstract: Postsurgical pain management remains a significant challenge. Liposome bupivacaine, as part of a multimodal analgesic regimen, has been shown to significantly reduce postsurgical opioid consumption, hospital length of stay (LOS), and hospitalization costs in gastrointestinal (GI) surgery, compared with intravenous (IV) opioid-based patient-controlled analgesia (PCA). Pooled results from open-label studies comparing a liposome bupivacainebased multimodal analgesic regimen with IV opioid PCA were analyzed. Patients $(n=191)$ who underwent planned surgery and received study drug (IV opioid PCA, n=105; multimodal analgesia, $n=86$ ) were included. Liposome bupivacaine-based multimodal analgesia compared with IV opioid PCA significantly reduced mean (standard deviation [SD]) postsurgical opioid consumption (38 [55] mg versus [vs] 96 [85] mg; $P<0.0001$ ), postsurgical LOS (median $2.9 \mathrm{vs}$ 4.3 days; $P<0.0001$ ), and mean hospitalization costs (US\$8,271 vs US $\$ 10,726 ; P=0.0109$ ). The multimodal analgesia group reported significantly fewer patients with opioid-related adverse events (AEs) than the IV opioid PCA group $(P=0.0027)$; there were no significant between-group differences in patient satisfaction scores at 30 days. A liposome bupivacaine-based multimodal analgesic regimen was associated with significantly less opioid consumption, opioid-related AEs, and better health economic outcomes compared with an IV opioid PCA-based regimen in patients undergoing GI surgery.

Study registration: This pooled analysis is based on data from Phase IV clinical trials registered on the US National Institutes of Health www.ClinicalTrials.gov database under study identifiers NCT01460485, NCT01507220, NCT01507233, NCT01509638, NCT01509807, NCT01509820, NCT01461122, NCT01461135, NCT01534988, and NCT01507246.

Keywords: analgesia, gastrointestinal surgery, postoperative pain, opioid analgesics, bupivacaine

\section{Introduction}

Most surgical patients experience significant (moderate-to-severe) pain following surgery. ${ }^{1,2}$ Surveys conducted over the past two decades show that despite efforts to improve peri- and postsurgical analgesia, the incidence and severity of postsurgical pain have remained relatively unchanged over time. ${ }^{1-3}$

Although opioid analgesics have demonstrated efficacy in the treatment of perioperative pain, ${ }^{4,5}$ their use is frequently associated with burdensome and sometimes costly adverse events (AEs). ${ }^{5,6}$ Large cohort studies have shown that patients experiencing opioid-related AEs tend to have significantly longer hospital stays, significantly higher hospital costs, and significantly higher readmission rates compared with patients without opioid-related AEs. ${ }^{7,8}$ Postsurgical pain is therefore often undermanaged and undertreated, ${ }^{6,9}$ partially as a result of concern over the prospect of opioid-related AEs. 
Overall, the most frequently reported opioid-related AEs in surgical patients are gastrointestinal (GI) in nature. ${ }^{6}$ GI opioid-related AEs are particularly burdensome in patients undergoing GI surgery, because these patients are already at high risk for experiencing GI motility problems (such as postoperative ileus); opioid use further exacerbates this risk. ${ }^{10-13}$ Even moderate doses of opioids, including hydromorphone-equivalent doses of as little as $2 \mathrm{mg} /$ day, have been associated with a significantly increased risk of opioid-related AEs and a longer hospital stay. ${ }^{11,14}$ Moreover, increased risk for GI opioid-related AEs occurs against a backdrop of other frequently reported opioid-related AEs; perhaps the most problematic of these are central nervous system effects such as somnolence and dizziness, which may contribute to falls and other secondary events ${ }^{6}$ such as respiratory depression.

The use of multimodal analgesia, targeting multiple pain pathways with a range of analgesic agents, has been strongly endorsed by the American Society of Anesthesiologists (ASA) and should be used whenever possible in surgery patients to help minimize opioid exposure. ${ }^{4}$ Liposome bupivacaine, a prolonged-release formulation of the local anesthetic bupivacaine (EXPAREL ${ }^{\circledR}$ [bupivacaine liposome injectable suspension], Pacira Pharmaceuticals, Inc., Parsippany, NJ, USA) indicated for administration into the surgical site to produce postsurgical analgesia, ${ }^{15}$ can be used as a central component of multimodal analgesic regimens for postsurgical pain management.

In a series of open-label Phase IV studies (designated IMPROVE, for Extended PaIn Relief Trial Utilizing the Infiltration of a Long-Acting Multivesicular LiPosome FoRmulation Of BupiVacaine, EXPAREL), a liposome bupivacainebased multimodal analgesic regimen was compared with a standard intravenous (IV) opioid-based regimen incorporating patient-controlled analgesia (PCA) in patients undergoing GI surgery (open or laparoscopic colectomy, or ileostomy reversal). ${ }^{16-19}$ Compared with a conventional opioid-based PCA regimen, the use of liposome bupivacaine was shown to significantly improve postsurgical outcomes in the individual studies, including reductions in opioid use, hospital length of stay (LOS), and hospitalization costs, although between-group differences did not reach statistical significance on every outcome measure in every study (Table 1). ${ }^{16-19}$

In this report, we present an analysis of pooled data across all of the IMPROVE studies. Pooling of data from these similarly designed studies allows for a more detailed assessment of efficacy and safety measures; the ability to pool the data from these studies was prespecified in the statistical analysis

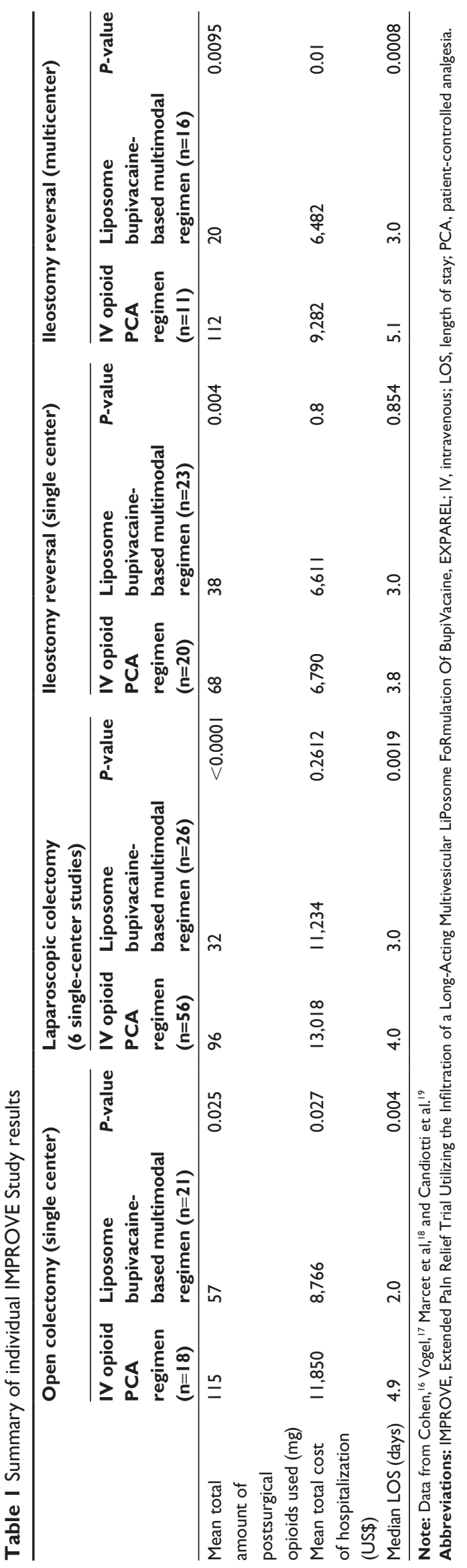


plan. The objective was to assess postsurgical analgesia, opioid use, and health economic outcomes associated with a liposome bupivacaine-based multimodal analgesic regimen, compared with an IV opioid-based PCA regimen, in patients undergoing GI surgery.

\section{Methods}

The IMPROVE studies were Phase IV, prospective, multicenter, open-label, sequential-cohort studies designed to evaluate the efficacy, safety, and health economic outcomes associated with a multimodal analgesic regimen incorporating intraoperatively administered liposome bupivacaine $266 \mathrm{mg}$, in comparison with postsurgical PCA using IV morphine or hydromorphone (opioid-based analgesic regimen). Of note, these studies were not designed to demonstrate whether or not liposome bupivacaine is effective; this has been done in multiple prior studies. ${ }^{20,21}$ Rather, these studies were designed to show whether or not a liposome bupivacaine-based multimodal therapeutic regimen had demonstrable and statistically significant pharmacoeconomic differences compared with a standard IV opioid-based PCA regimen.

All study protocols were approved by the relevant institutional review boards or independent ethics committees, and the studies were conducted in accordance with the International Conference on Harmonisation Good Clinical Practice Guidelines and/or the US Food and Drug Administration Title 21 Code of Federal Regulations Part 56. Written informed consent was obtained from all patients prior to enrollment in each study.

Adults aged 18 years or older who were undergoing open colectomy, laparoscopic colectomy, or ileostomy reversal were eligible for study inclusion. Key exclusion criteria were pregnancy; severe hepatic impairment; a history of drug or alcohol abuse; any concomitant psychiatric, psychological, or other condition that could interfere with study participation; intraoperative use of opioids (other than fentanyl and ana$\operatorname{logs}$ ), any other analgesics (including local anesthetics or anti-inflammatory drugs); or use of alvimopan.

Except for the differences in surgical models, methodology was similar across studies, and has been described in previous publications. ${ }^{16-19}$ Briefly, patients in each study were enrolled in sequential cohorts (IV opioid PCA cohort first, followed by liposome bupivacaine-based multimodal analgesia cohort). All screening procedures were completed within 2 weeks of surgery. On the day of surgery (study day 1), treatment of patients assigned to IV opioid PCA therapy was initiated as soon as possible after surgery. For patients assigned to multimodal analgesia, a single administration of liposome bupivacaine $266 \mathrm{mg}$ in $0.9 \%$ normal saline was injected at the surgical site using a moving-needle technique prior to wound closure. The $266 \mathrm{mg}$ dose of liposome bupivacaine was expanded to a total volume of $40 \mathrm{~mL}$ in studies involving open and laparoscopic colectomy procedures, and to a total volume of $30 \mathrm{~mL}$ in studies involving ileostomy reversal. Patients in the multimodal analgesia cohort also received a single administration of IV ketorolac $30 \mathrm{mg}$ (or alternative IV nonsteroidal anti-inflammatory drug) at the end of surgery, followed by oral or IV acetaminophen $1,000 \mathrm{mg}$ plus oral ibuprofen $600 \mathrm{mg}$ given every 6 hours (starting with patient tolerance of oral intake) for 72 hours after surgery.

Patients in both treatment groups had access to rescue analgesia as needed (IV opioid and/or oral oxycodone/ acetaminophen $5 \mathrm{mg} / 325 \mathrm{mg}$ ); the maximum amount of acetaminophen allowed per day was no more than 4,000 mg. Rescue analgesia was continued as needed and the amount of postsurgical opioid consumption was recorded through time of discharge or study day 30, whichever was earlier. All emergent AEs and serious AEs were recorded through study day 30; on day 30, AEs were assessed and follow-up surveys on patient-reported outcomes (postsurgical complications and patient satisfaction with analgesia) were conducted.

Some of the liposome bupivacaine vials supplied for the study were slightly ( $\leq 7 \%$ ) outside of the prespecified range for release of bupivacaine from the multivesicular liposomes. This had the potential to result in a release of up to $19 \mathrm{mg}$ less bupivacaine than anticipated over the first 48 hours after administration, which was not expected to have a significant effect on the outcome of the study but may be perceived as a potential study limitation. Since the defective liposome bupivacaine vials had potential to release less bupivacaine than anticipated, any bias caused by this would have been in favor of the comparator regimen.

The primary outcome measures were total amount of opioid consumption after surgery until discharge or day 30 , whichever was earlier; estimated total cost of hospitalization until discharge or through day 30; and LOS, defined as time (hours) from surgical wound closure until discharge or through day 30. Medical billing claim forms were used to ascertain hospital costs. Secondary outcome measures included incidence of opioid-related AEs (defined as somnolence, respiratory depression, hypoventilation, hypoxia, dry mouth, nausea, vomiting, constipation, sedation, confusion, pruritus, urinary retention, or postoperative ileus, assessed as an efficacy measure); time to first postsurgical opioid administration; patient overall satisfaction with postsurgical 
analgesia (assessed on day 30 using a five-point Likert scale); patient responses to a follow-up survey (on day 30) regarding hospital readmissions, unplanned medical visits, and healthrelated problems during recovery; and emergent postsurgical AEs and serious AEs reported through day 30.

For data analysis, the safety population included all patients who underwent the planned surgery. The efficacy population included all patients who underwent surgery as planned and did not receive intraoperative administration of any analgesics (other than fentanyl or analogs), local anesthetics, anti-inflammatory agents, or alvimopan; patients assigned to the liposome bupivacaine-based multimodal analgesia group must also have received liposome bupivacaine. Study sample sizes were not based on formal statistical power calculations. Between-group comparisons for continuous efficacy measures (eg, opioid consumption) were conducted using an analysis of variance (ANOVA) with group and study in the model, with two-sided $95 \%$ confidence intervals (CIs) calculated for between-group differences in geometric means for cost data and arithmetic means for other efficacy measures. The ANOVA was performed on natural logarithm transformed data. To calculate total opioid consumption, opioid medication amounts were converted to morphine equivalents to facilitate comparisons. Comparisons for categorical efficacy measures were conducted using Fisher's exact test. LOS and time to first postsurgical opioid administration were summarized using the Kaplan-Meier method; between-group comparisons were conducted using a log-rank test. All between-group comparisons were twosided, with the significance level set at 0.05 ; no adjustment of significance levels was made for multiple tests.

\section{Results}

The IMPROVE studies were conducted at 13 centers by 13 investigators. Across the IMPROVE studies, a total of 223 patients underwent surgery; 191 patients received the study drug as prescribed (105 in the IV opioid PCA group, 86 in the liposome bupivacaine-based multimodal analgesia group). Of the 191 patients included in the analysis, 39 underwent open colectomy, 82 underwent laparoscopic colectomy, and 70 underwent ileostomy reversal. ${ }^{16-19}$ Patient demographics and baseline characteristics for the safety population are summarized in Table 2; overall, the treatment groups were well-matched with respect to age, sex, racial composition, body mass index, and baseline ASA physical status.

With respect to primary outcome measures, the mean (standard deviation [SD]) postsurgical opioid consumption in the liposome bupivacaine-based multimodal analgesia group was 38 (55) mg compared with 96 (85) $\mathrm{mg}$ in the IV opioid
Table 2 Demographics and baseline characteristics (safety population)

\begin{tabular}{|c|c|c|}
\hline Variable & $\begin{array}{l}\text { IV opioid } \\
\text { PCA regimen } \\
(n=\mid 22)\end{array}$ & $\begin{array}{l}\text { Liposome } \\
\text { bupivacaine-based } \\
\text { multimodal } \\
\text { regimen }(n=\mid 0 I)\end{array}$ \\
\hline Age, mean (SD), years & $56(16)$ & $53(15)$ \\
\hline \multicolumn{3}{|l|}{ Sex, n (\%) } \\
\hline Male & $66(54)$ & $49(49)$ \\
\hline Female & $56(46)$ & $52(52)$ \\
\hline \multicolumn{3}{|l|}{ Race, n (\%) } \\
\hline White & $94(77)$ & $81(80)$ \\
\hline Black & $18(15)$ & $15(15)$ \\
\hline Asian & $2(2)$ & $2(2)$ \\
\hline Other & $8(7)$ & $3(3)$ \\
\hline $\begin{array}{l}\text { Body mass index, } \\
\text { mean (SD), } \mathrm{kg} / \mathrm{m}^{2}\end{array}$ & $27.5(6.1)$ & $26.7(5.6)$ \\
\hline \multicolumn{3}{|l|}{$\begin{array}{l}\text { ASA physical status } \\
\text { classification, } \mathrm{n}(\%)\end{array}$} \\
\hline I & $5(4)$ & $2(2)$ \\
\hline 2 & $67(55)$ & $61(60)$ \\
\hline 3 & $47(39)$ & $38(38)$ \\
\hline 4 & $3(3)$ & 0 \\
\hline
\end{tabular}

Abbreviations: ASA, American Society of Anesthesiologists; IV, intravenous; PCA, patient-controlled analgesia; SD, standard deviation.

PCA group ( $P<0.0001$; Figure 1). As shown in Figure 2, the median (range) LOS following surgery was 2.9 (0.8-29.9) days in the multimodal analgesia group, compared with 4.3 $(0-31.9)$ days in the IV opioid PCA group $(P<0.0001)$. The geometric mean total cost of hospitalization (Figure 3) was US\$8,271 in the multimodal analgesia group, compared with US $\$ 10,726$ in the IV opioid PCA group $(P=0.0109)$.

Opioid-related AEs observed in the efficacy population are summarized in Table 3. The proportion of patients who experienced an opioid-related AE was significantly higher in the IV opioid PCA group (27\%) compared with the liposome bupivacaine-based multimodal analgesia group ( $9 \%$; $P=0.0027)$. The most frequently reported opioid-related AE was nausea, reported by a significantly greater proportion of patients in the IV opioid PCA group (19\%) than in the multimodal analgesia group $(5 \% ; P=0.0036)$. The mean (SD) number of opioid-related AEs per patient was 0.4 (0.7) and $0.1(0.3)$ in the IV opioid PCA and multimodal analgesia groups, respectively $(P=0.0014)$.

Results for other secondary outcome measures in the efficacy population are summarized in Table 4. The time to first postsurgical opioid use was significantly longer for patients in the liposome bupivacaine-based multimodal analgesia group compared with the IV opioid PCA group (median 1.2 versus [vs] 0.6 hours, respectively; $P<0.0001$ ). The proportion of patients reporting that they were extremely satisfied with postsurgical analgesia was slightly higher 


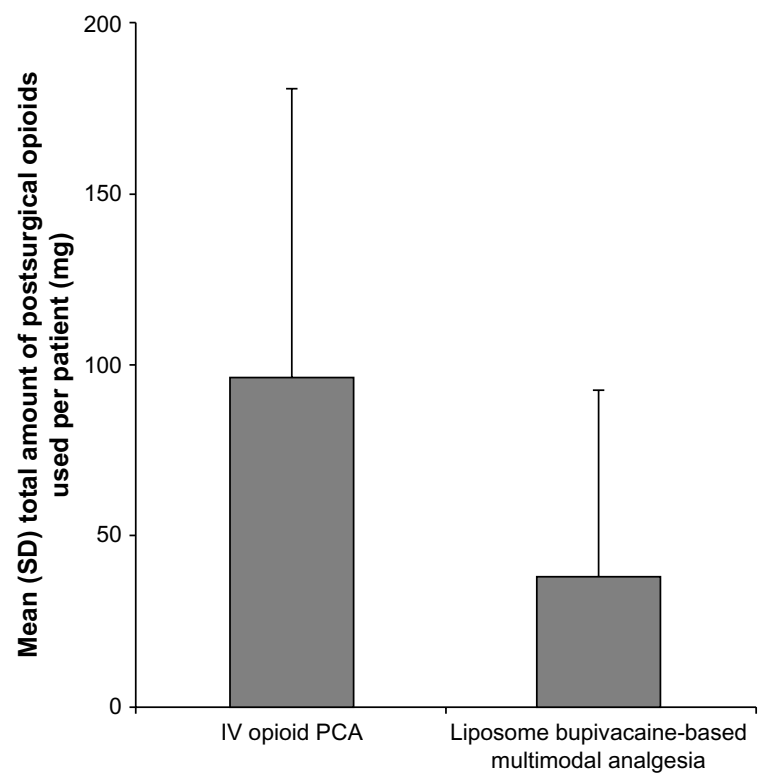

Figure I Mean per-patient postsurgical opioid consumption; amounts are expressed in morphine mg equivalents.

Notes: Error bars represent SD; $P<0.0001$ for the between-group comparison. Abbreviations: IV, intravenous; PCA, patient-controlled analgesia; SD, standard deviation.

in the multimodal analgesia group (59\%) compared with the IV opioid PCA group (47\%), although between-group differences for satisfaction scores at 30 days did not reach statistical significance $(P=0.2407$ for between-group comparison of distribution of patient responses). There

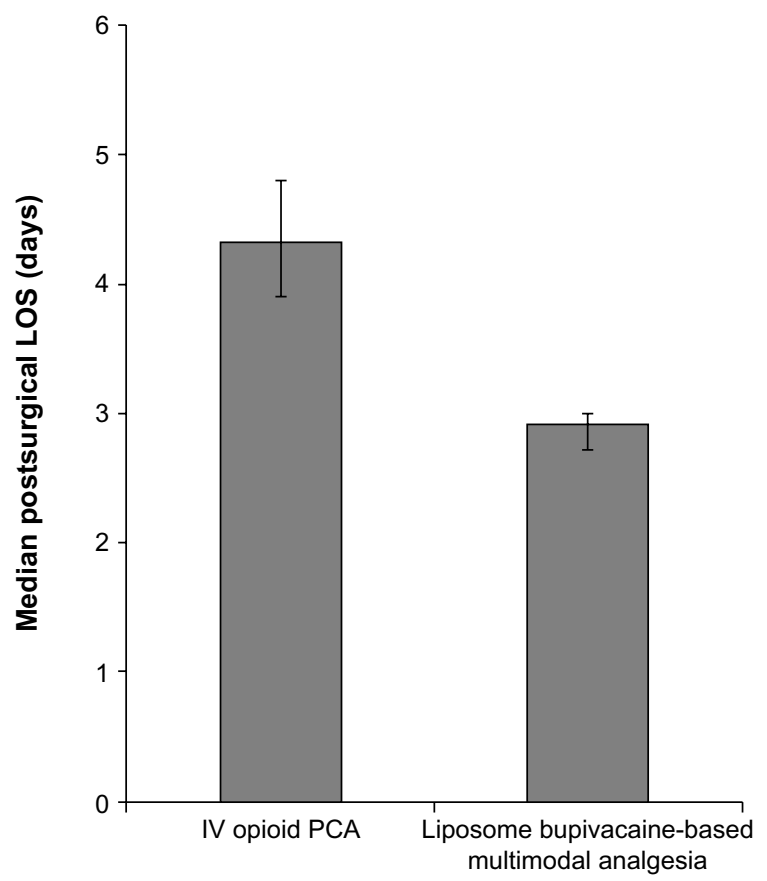

Figure 2 Median postsurgical LOS in days.

Notes: Error bars represent $95 \% \mathrm{Cls}$ for the median; $P<0.000 \mathrm{I}$ for the betweengroup comparison.

Abbreviations: Cls, confidence intervals; IV, intravenous; LOS, length of stay; PCA, patient-controlled analgesia.

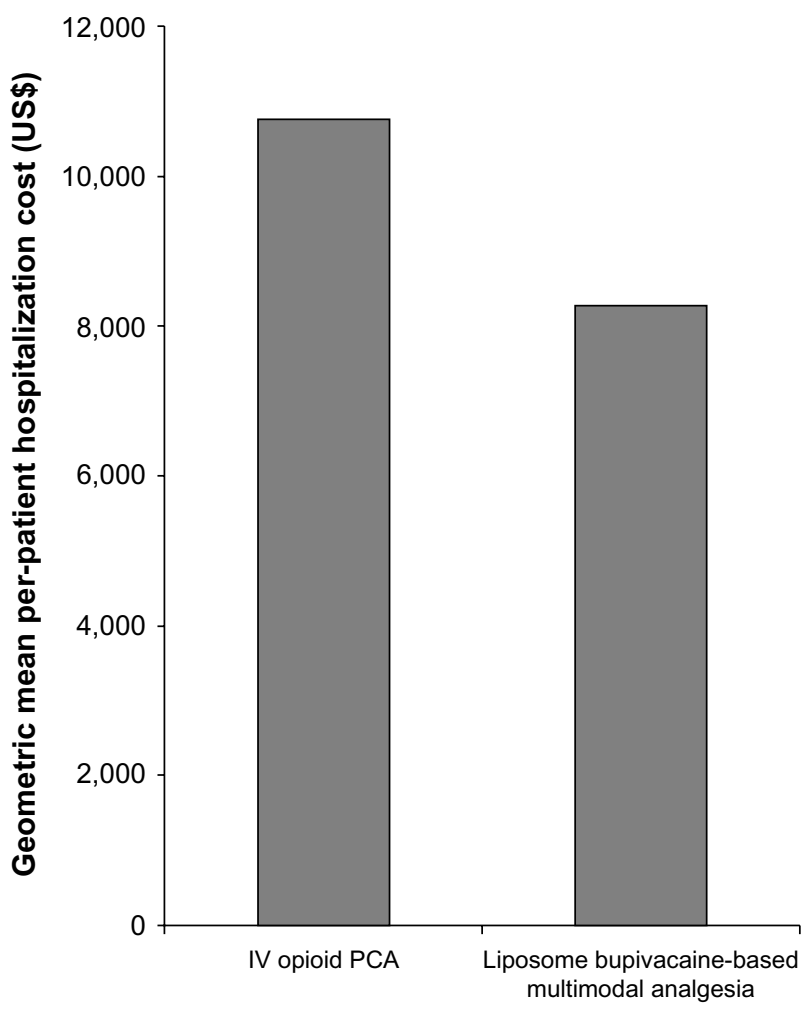

Figure 3 Geometric mean per-patient total cost of hospitalization (US\$). Note: $P=0.0109$ for the between-group comparison.

Abbreviations: IV, intravenous; PCA, patient-controlled analgesia.

were no significant between-group differences in the proportions of patients requiring hospital readmission, making unplanned postsurgical visits with health care providers, contacting health care providers to discuss recovery, or those experiencing postsurgical health problems/changes in health, although all between-group differences favored the liposome bupivacaine-based multimodal analgesia group.

Table 3 Summary of opioid-related adverse events (efficacy population)

\begin{tabular}{lll}
\hline & $\begin{array}{l}\text { IV opioid } \\
\text { PCA regimen } \\
(\mathbf{n = 1 0 5 )}\end{array}$ & $\begin{array}{l}\text { Liposome } \\
\text { bupivacaine- } \\
\text { based multimodal } \\
\text { regimen (n=86) }\end{array}$ \\
\hline $\begin{array}{lll}\text { Patients with any opioid- } \\
\text { related adverse event, n (\%) }\end{array}$ & $28(27)$ & $8(9)^{\mathrm{a}}$ \\
Nausea & $20(19)$ & $4(5)^{\mathrm{b}}$ \\
$\begin{array}{l}\text { Vomiting } \\
\text { Urinary retention }\end{array}$ & $6(6)$ & $2(2)$ \\
Pruritus & $5(5)$ & $\mathrm{I}(\mathrm{I})$ \\
Postoperative ileus & $5(5)$ & 0 \\
Constipation & $3(3)$ & 0 \\
Somnolence & 0 & $\mathrm{I}(\mathrm{I})$ \\
\hline
\end{tabular}

Notes: ${ }^{a} P=0.0027$ for the between-group comparison; ${ }^{b} P=0.0036$ for the betweengroup comparison.

Abbreviations: IV, intravenous; PCA, patient-controlled analgesia. 
Table 4 Results for other secondary efficacy outcome measures (efficacy population)

\begin{tabular}{lll}
\hline & $\begin{array}{l}\text { IV opioid } \\
\text { PCA } \\
\text { regimen } \\
(\mathbf{n = 1 0 5 )}\end{array}$ & $\begin{array}{l}\text { Liposome } \\
\text { bupivacaine- } \\
\text { based multimodal } \\
\text { regimen (n=86) }\end{array}$ \\
\hline $\begin{array}{l}\text { Median (range) time to first } \\
\text { opioid use, hours }\end{array}$ & $0.6(0-70)$ & $1.2(0.2-120)^{\mathrm{a}}$ \\
$\begin{array}{l}\text { Proportion (\%) of patients who } \\
\text { reported being extremely }\end{array}$ & 47 & 59 \\
$\begin{array}{l}\text { satisfied with their postsurgical } \\
\text { pain treatment }\end{array}$ & \\
$\begin{array}{l}\text { Proportion (\%) of patients who } \\
\text { required hospital readmission } \\
\text { after surgery }\end{array}$ & 7 & 6 \\
$\begin{array}{l}\text { Proportion (\%) of patients who } \\
\text { made unplanned visits with a } \\
\text { health care provider after surgery }\end{array}$ & 12 & 12 \\
$\begin{array}{l}\text { Proportion (\%) of patients who } \\
\text { made contact with a health care } \\
\text { provider to discuss recovery } \\
\text { after surgery }\end{array}$ & 14 & 9 \\
$\begin{array}{l}\text { Proportion (\%) of patients who } \\
\text { experienced health problems or } \\
\text { changes in health after surgery }\end{array}$ & 15 & 8 \\
\hline
\end{tabular}

Note: ${ }^{p}<0.000$ I for the between-group comparison.

Abbreviations: IV, intravenous; PCA, patient-controlled analgesia.

AEs observed in the safety population are summarized in Table 5; 62\% of patients in the IV opioid PCA group, and $42 \%$ in the liposome bupivacaine-based multimodal analgesia group, experienced at least one AE. Overall, the most frequently reported AEs included nausea (15\%), diarrhea

Table 5 Summary of adverse events reported in equal to or greater than $3 \%$ of patients in either study group (safety population)

\begin{tabular}{lll}
\hline Adverse events & $\begin{array}{l}\text { IV opioid PCA } \\
\text { regimen } \\
(\mathbf{n}=\mathbf{1 2 2})\end{array}$ & $\begin{array}{l}\text { Liposome } \\
\text { bupivacaine- } \\
\text { based multimodal } \\
\text { regimen }(\mathbf{n}=\mathbf{1 0 1})\end{array}$ \\
\hline Patients with any adverse & $75(62)$ & $42(42)$ \\
event, $\mathrm{n}(\%)$ & & \\
Nausea & $27(22)$ & $6(6)$ \\
Diarrhea & $7(6)$ & $7(7)$ \\
Abdominal pain & $8(7)$ & $5(5)$ \\
Abdominal distension & $8(7)$ & $2(2)$ \\
Vomiting & $7(6)$ & $3(3)$ \\
Headache & $8(7)$ & 0 \\
Urinary retention & $6(5)$ & $2(2)$ \\
Anemia & $4(3)$ & $2(2)$ \\
Hypokalemia & $1(<1)$ & $4(4)$ \\
Pruritus & $5(4)$ & 0 \\
Back pain & $4(3)$ & 0 \\
Leukocytosis & $4(3)$ & 0 \\
Urinary tract infection & $4(3)$ & 0 \\
\hline Abbrevations: & &
\end{tabular}

Abbreviations: IV, intravenous; PCA, patient-controlled analgesia.
(6\%), abdominal pain (6\%), abdominal distension (5\%), and vomiting (5\%). There were 17 patients (14\%) in the IV opioid PCA group who experienced AEs considered to be related to the study drug. These AEs included 14 events of nausea, five of pruritus, two of headache, and one event of somnolence. One patient in the multimodal analgesia group experienced an $\mathrm{AE}$ related to the study drug (one incident of procedural pain). Thirteen patients (11\%) in the IV opioid PCA group and twelve (12\%) in the multimodal analgesia group experienced serious AEs; none of these events were considered to be related to the study drug by the investigators.

\section{Discussion}

The IMPROVE studies applied a common study design to three frequently performed GI surgery types. This facilitated the analysis of a pooled data set (a step that was prespecified in the individual study protocols), incorporating a larger and more diverse patient population, for the comparison of two analgesic regimens in the treatment of postsurgical pain.

This analysis of patients undergoing open colectomy, laparoscopic colectomy, or ileostomy reversal surgery showed that the use of liposome bupivacaine-based multimodal analgesic therapy for postsurgical analgesia, compared with a conventional IV opioid-based PCA regimen, resulted in significantly reduced mean postsurgical opioid consumption (reduction of $61 \%$ in total opioid consumption), median postsurgical LOS (by approximately 1.5 days), and mean perpatient hospitalization costs (by approximately US $\$ 2,450$ ).

The overall incidence of AEs was lower in the liposome bupivacaine-based multimodal analgesia group than in the IV opioid PCA group, suggesting that liposome bupivacainebased multimodal analgesia is well-tolerated in the postsurgical setting. Of particular interest was the highly significant relative reduction of about $65 \%$ in the incidence of opioidrelated AEs, which are known to be an important driver of increased LOS and cost in the postsurgical setting. ${ }^{7,8}$

It is also interesting to note that the observed improvements in objective outcome measures (ie, reduced opioid consumption, LOS, hospitalization costs, and opioid-related AE incidence) did not appear to be counterbalanced by lower levels of patient-reported satisfaction with pain treatment at 30 days. It is possible that the five-point Likert scale used to assess patient satisfaction was insufficiently sensitive to detect real improvements, or that the concept of "satisfaction" is affected by additional subjective factors (eg, anticipated pain vs actual pain) in addition to perceived pain intensity. It is interesting to note, however, that the patient-reported satisfaction ratings in this study were consistent with those 
from prior studies. ${ }^{22,23}$ Also, since there was a 30-day span between surgery and the assessment of satisfaction, patient recall may have been a confounding factor affecting the results of the survey. Because pain intensity scores were not included in the outcome assessments, it is difficult to draw firm conclusions regarding the correlation between objective and patient-reported measures in this analysis.

The average savings of nearly US $\$ 2,500$ per patient in hospitalization costs observed in the liposome bupivacainebased multimodal group is probably a reflection of the clinical benefits observed on the other outcome measures (less opioid consumption, shorter hospital stay, fewer AEs overall, and fewer opioid-related AEs). Based on these observations, it appears that the product costs related to the liposome bupivacaine-based multimodal analgesic regimen may have been offset by the improved outcomes that were observed.

Nevertheless, our results should be viewed in the context of study limitations, including dependence on a post-hoc analysis of data from open-label studies, which carry the potential risk of investigator bias. Since the multimodal analgesia groups received analgesics other than liposome bupivacaine (ie, ketorolac, acetaminophen, and ibuprofen), the treatment effects specifically attributable to liposome bupivacaine are difficult to quantify. However, this weakness was mitigated by the fact that patients in the IV opioid PCA group were allowed oral opioid/nonopioid combinations of medications, thus allowing them some of the benefits of multimodal therapy. Sequential enrollment, rather than randomized assignment, was used to simplify study operations and to minimize study-related burden on surgeons, patients, and site staff. This approach may have been a potential source of bias that could limit interpretation of the study results. In addition, as noted, pain intensity scores were not assessed, complicating the potential link between improvements in objective measures and improved patient experiences.

\section{Conclusion}

Despite the limitations of this analysis, liposome bupivacaine-based multimodal therapy demonstrated clinically meaningful and statistically significant advantages compared with a standard IV opioid-based PCA regimen, including reductions in the amount of opioids used, incidence of opioidrelated AEs, postsurgical LOS, and total hospital costs.

\section{Acknowledgments}

Editorial assistance was provided by Michael Morren, RPh, MBA, of Peloton Advantage, LLC (Parsippany, NJ, USA), supported by Pacira Pharmaceuticals, Inc. The authors were fully responsible for the content, editorial decisions, and opinions expressed in the current article. No author received an honorarium related to the development of this manuscript.

\section{Disclosure}

Dr Cohen is a consultant and speaker for Pacira Pharmaceuticals, Inc. Dr Vogel has no conflicts of interest to report. Dr Marcet has received research funding from Pacira Pharmaceuticals, Inc. Dr Candiotti has received research funding from Pacira Pharmaceuticals, Inc.

\section{References}

1. Apfelbaum JL, Chen C, Mehta SS, Gan TJ. Postoperative pain experience: results from a national survey suggest postoperative pain continues to be undermanaged. Anesth Analg. 2003;97(2): 534-540.

2. Gan TJ, Habib AS, White W, Miller T. Postoperative pain continues to be undermanaged [abstract]. Presented at: Annual Fall Pain Meeting and Workshops of the American Society of Regional Anesthesia and Pain Medicine; November15-18, 2012; Miami Beach, FL.

3. Warfield CA, Kahn $\mathrm{CH}$. Acute pain management. Programs in US hospitals and experiences and attitudes among US adults. Anesthesiology. 1995;83(5):1090-1094.

4. American Society of Anesthesiologists Task Force on Acute Pain Management. Practice guidelines for acute pain management in the perioperative setting: an updated report by the American Society of Anesthesiologists Task Force on Acute Pain Management. Anesthesiology. 2012;116(2):248-273.

5. Oderda GM, Said Q, Evans RS, et al. Opioid-related adverse drug events in surgical hospitalizations: impact on costs and length of stay. Ann Pharmacother. 2007;41(3):400-406.

6. Wheeler M, Oderda GM, Ashburn MA, Lipman AG. Adverse events associated with postoperative opioid analgesia: a systematic review. J Pain. 2002;3(3):159-180.

7. Kessler ER, Shah M, Gruschkus K, Raju A. Cost and quality implications of opioid-based postsurgical pain control using administrative claims data from a large health system: opioid-related adverse events and their impact on clinical and economic outcomes. Pharmacotherapy. 2013;33(4):383-391.

8. Oderda GM, Gan TJ, Johnson BH, Robinson SB. Effect of opioid-related adverse events on outcomes in selected surgical patients. J Pain Palliat Care Pharmacother. 2013;27(1):62-70.

9. Wu CL, Raja SN. Treatment of acute postoperative pain. Lancet. 2011;377(9784):2215-2225.

10. Senagore AJ. Pathogenesis and clinical and economic consequences of postoperative ileus. Am J Health Syst Pharm. 2007;64(20 Suppl 13): S3-S7.

11. Barletta JF, Asgeirsson T, Senagore AJ. Influence of intravenous opioid dose on postoperative ileus. Ann Pharmacother. 2011;45(7-8): 916-923.

12. Artinyan A, Nunoo-Mensah JW, Balasubramaniam S, et al. Prolonged postoperative ileus-definition, risk factors, and predictors after surgery. World J Surg. 2008;32(7):1495-1500.

13. Cali RL, Meade PG, Swanson MS, Freeman C. Effect of morphine and incision length on bowel function after colectomy. Dis Colon Rectum. 2000;43(2):163-168.

14. Zhao SZ, Chung F, Hanna DB, Raymundo AL, Cheung RY, Chen C. Dose-response relationship between opioid use and adverse effects after ambulatory surgery. J Pain Symptom Manage. 2004;28(1):35-46.

15. Exparel $^{\circledR}$ (bupivacaine liposome injectable suspension) [prescribing information]. Parsippany, NJ: Pacira Pharmaceuticals, Inc.; 2012. 
16. Cohen SM. Extended pain relief trial utilizing infiltration of Exparel ${ }^{\circledR}$, a long-acting multivesicular liposome formulation of bupivacaine: a Phase IV health economic trial in adult patients undergoing open colectomy. J Pain Res. 2012;5:567-572.

17. Vogel JD. Liposome bupivacaine (EXPAREL $\left.{ }^{\circledR}\right)$ for extended pain relief in patients undergoing ileostomy reversal at a single institution with a fast-track discharge protocol: an IMPROVE Phase IV health economics trial. J Pain Res. 2013;6:605-610.

18. Marcet JE, Nfonsam VN, Larach S. An extended paIn relief trial utilizing the infiltration of a long-acting Multivesicular liPosome foRmulation Of bupiVacaine, EXPAREL (IMPROVE): a Phase IV health economic trial in adult patients undergoing ileostomy reversal. J Pain Res. 2013;6:549-555.

19. Candiotti KA, Sands LR, Lee E, et al. Liposome bupivacaine for postsurgical analgesia in adult patients undergoing laparoscopic colectomy: results from prospective phase IV sequential cohort studies assessing health economic outcomes. Curr Ther Res. 2014;76:1-6.
20. Bergese SD, Ramamoorthy S, Patou G, Bramlett K, Gorfine SR, Candiotti KA. Efficacy profile of liposome bupivacaine, a novel formulation of bupivacaine for postsurgical analgesia. J Pain Res. 2012;5: 107-116.

21. Dasta J, Ramamoorthy S, Patou G, Sinatra R. Bupivacaine liposome injectable suspension compared with bupivacaine $\mathrm{HCl}$ for the reduction of opioid burden in the postsurgical setting. Curr Med Res Opin. 2012;28(10):1609-1615.

22. Gorfine SR, Onel E, Patou G, Krivokapic ZV. Bupivacaine extendedrelease liposome injection for prolonged postsurgical analgesia in patients undergoing hemorrhoidectomy: a multicenter, randomized, double-blind, placebo-controlled trial. Dis Colon Rectum. 2011;54(12): 1552-1559.

23. Smoot JD, Bergese SD, Onel E, Williams HT, Hedden W. The efficacy and safety of DepoFoam bupivacaine in patients undergoing bilateral, cosmetic, submuscular augmentation mammoplasty: a randomized, double-blind, active-control study. Aesthet Surg J. 2012;32(1):69-76.
Journal of Pain Research

\section{Publish your work in this journal}

The Journal of Pain Research is an international, peer-reviewed, open access, online journal that welcomes laboratory and clinical findings in the fields of pain research and the prevention and management of pain. Original research, reviews, symposium reports, hypothesis formation and commentaries are all considered for publication.

\section{Dovepress}

The manuscript management system is completely online and includes a very quick and fair peer-review system, which is all easy to use. Visit http://www.dovepress.com/testimonials.php to read real quotes from published authors. 